\title{
Central Composite Design to Optimizate the Derivatization Procedure for Analysis of Biogenic Amines by HPLC-UV
}

\author{
Ángela K. Argotty Salazar*,a,b,c and Juan J. Lozada Castro ${ }^{*, a, b}$ \\ ${ }^{a}$ Departamento de Química, Facultad de Ciencias Naturales y Exactas, ${ }^{b}$ Grupo de Invetigación \\ Estudio de Sistemas Contaminantes (GIESIC) and ${ }^{c}$ Grupo de Invetigación Salud Pública, Centro \\ de Estudios en Salud (CESUN), Universidad de Nariño, Clle 18 Cr 50 Ciudadela Universitaria \\ Torobajo, 52001 Pasto, Nariño, Colombia
}

\begin{abstract}
A simple benzoylation procedure was optimized for the biogenic amines derivatization prior to high-performance liquid chromatography determination. The significant factors affecting biogenic amine benzoylation yield were optimized by central composite design (CCD). The obtained optimal conditions resulted in a chromatographic peaks area increase with fewer interferences. Moreover, the efficiency parameters for chromatographic separation of putrescine, histamine and tyramine were determined under optimum operating conditions, which included: capacity factors or retention $\left(\mathrm{k}^{\prime}\right)=2.5-4.2$, selectivity factors $(\alpha)>1$ and resolution values $\left(\mathrm{R}_{\mathrm{s}}\right)>1.5$, indicating that the column provided good separation of the analytes. The optimized method was applied in spiked fish samples with standard solutions of putrescine, histamine and tyramine at concentrations of 50, 80 and $50 \mathrm{mg} \mathrm{L}^{-1}$, respectively, to achieve recovery rates in a range from 90.89 to $96.65 \%$ for putrescine; 93.36 to $95.87 \%$ for histamine; 86.57 to $93.33 \%$ for tyramine, with the relative standard deviation (RSD) less than $4 \%$.
\end{abstract}

Keywords: biogenic amines, derivatization, benzoyl chloride, optimization

\section{Introduction}

Fish farming has had gradual growth in the Department of Nariño, and the conditions for farming development are limited due to poor control of environmental and sanitation conditions in the production chain processes. These limitations, together with the susceptibility of aquaculture products to microbial attack (due to its high content of water and protein) facilitate the decomposition of the species postmortem, and give rise to the toxins formation called biogenic amines (BAs), which constitute a high risk for consumers' health.

Numerous analytical methods have been developed to determine the BAs content of different foods. ${ }^{1-3}$ These range from simple colorimetric and fluorimetric methods to more sophisticated methods such as chromatography (GC, HPLC, HPTLC, etc.).

The first colorimetric methods published by the $\mathrm{AOAC}^{4}$ were based on the histamine extraction with methanol and the subsequent reaction of the histamine with ninhydrin for quantification. These methods are not

*e-mail: angeluz-j@hotmail.com,jjlccc@hotmail.com used today because they are tedious and require special attention to the procedure details such as sample previous purification. ${ }^{5,6}$ The fluorimetric methods described by $\mathrm{AOAC}^{7}$ have also been used to determine histamine in food. This method is based on histamine extraction with methanol and the subsequent derivatization of the histamine with $o$-phthalaldehyde (OPA), to produce a fluorescent compound that is determined by a fluorimeter. ${ }^{8}$ This method has significant interferences and is limited to histamine.

More commonly, chromatographic methods are used, specifically high performance liquid chromatography (HPLC), gas chromatography (GC), high performance thin layer chromatography (HPTLC) and, to a lesser extent, the traditional thin layer chromatography (TLC). These methods have been combined with different detection systems such as ultraviolet (UV), fluorescence, etc., and offer a great advantage over previously mentioned methods because they allow the simultaneous analysis of histamine and other BAs in different foods. ${ }^{9}$

Given the fact that the most widely used technique for BAs determination is HPLC and that this requires a derivatization process (due to the chromophores absence in these compounds), various HPLC methods have been 
proposed. For instance, researchers use HPLC based in an acid extraction with trichloroacetic (TCA) or perchloric acid (PCA), and the subsequent BAs derivatization, either before or after separating them in the column chromatographic. The main derivatizing reagents used are benzoyl chloride, dansyl chloride and OPA..$^{10,11}$ To separate, different types of column chromatography has been used such as $\mathrm{C} 18$ columns ${ }^{12}$ or ion exchange columns, mainly cationic exchange. ${ }^{13}$

Given that the quantity determination of BAs in food and meat products is very important to human health, it is essential to have a method that can quantify a large BAs number simultaneously. Such a technique should be highly selective, highly sensitive and very efficient, and should involve a process of optimizing conditions of samples preparation and chromatographic parameters. In this work, we optimized the process of derivatization of BAs, and determined the optimal conditions to separate, identify and quantify the products involved in the derivatization.

\section{Experimental}

\section{Reagents, equipment and methods}

\section{Reagents}

Putrescine, histamine and tyramine (99\%) were obtained and used from Sigma; benzoyl chloride (99\%) from Merck; $\mathrm{NaCl}$ (99.9\%) from Carlo Erba; ethyl ether (99.9\%) from Burdick AR-ACS Jackson; HPLC-grade methanol from Burdick Jackson; and gaseous nitrogen grade 5. From the solid patterns, a solution of $1000 \mathrm{mg} \mathrm{L}^{-1}$ in $0.1 \mathrm{~mol} \mathrm{~L}^{-1} \mathrm{HCl}$ was prepared. For the dilution, the working solutions were prepared in the linear range $1-50 \mathrm{mg} \mathrm{L}^{-1}$ for putrescine; 1-175 $\mathrm{mg} \mathrm{L}^{-1}$ for tyramine and 5-125 $\mathrm{mg} \mathrm{L}^{-1}$ for histamine.

\section{Equipment}

The following equipment were used: HPLC Agilent 1200, consisting of a quaternary pump Agilent 1200 series G1311A; UV detector UV G1314B; thermostatic compartment of chromatographic column G1316A; column Agilent zorbax XDB C18 $(250 \times 4.6 \mathrm{~mm}, 5 \mu \mathrm{m})$; and an auto-sampler ALS G1329A.

\section{Methods}

The analytical methodology developed was optimized by experimental design using multiple response analysis with statistical software Statgraphics Centurion XV-15.2.06.

\section{Chromatographic conditions for biogenic amines analysis}

The chromatographic conditions used for the separation of BAs derivatives were optimized due to bibliography discrepancies. For this, a fractional factorial experimental design $3^{2}$ was applied with the derivatization conditions recommended by Zarei et al. ${ }^{14}$ The chromatographic parameters evaluated were: flow rate, column temperature, and wavelength within the following ranges, as presented in Table 1. The response variables considered for the results analysis were: peaks area, $t_{R}$ (retention time) and $\mathrm{R}_{\mathrm{s}}$ (chromatographic resolution between peaks).

Table 1. Parameters evaluated in the chromatographic optimization

\begin{tabular}{lcc}
\hline Parameter & Minimum value & Maximum value \\
\hline Flow rate $/\left(\mathrm{mL} \mathrm{min}^{-1}\right)$ & 0.5 & 1.0 \\
Column temperature $/{ }^{\circ} \mathrm{C}$ & 20 & 40 \\
Wavelength $/ \mathrm{nm}$ & 230 & 275 \\
\hline
\end{tabular}

Once the best chromatographic conditions were established, we proceeded to establish settings of the mobile phase composition in order to decrease the retention factor of the analytes and to improve chromatographic resolution. For this, isocratics analysis were evaluated with the mobile phase $\mathrm{MeOH}: \mathrm{H}_{2} \mathrm{O}$ in proportions of 50:50, 70:30 and 85:15 (v/v) as well as analysis with elution gradient.

\section{Optimization of derivatization process of biogenic amines}

Due to the presence of peaks in chromatogram, other than those of interest that negatively affected the formation of tyramine derivative (by decreasing or inhibiting its chromatographic signal), the derivatization reaction was optimized to reduce or eliminate interferences produced in the derivatization reaction.

The derivatization process was optimized with the derivatization conditions recommended by Zarei et al. ${ }^{14}$ In order to determine which of the factors were critical in the derivatization process, a factorial screening design $2^{3}$ was performed with a center point, resulting in a total of 9 experiments. The response variables for each experiment included the chromatographic area of significant peaks and the number of interfering chromatographic peaks. All injections were made in duplicate $(\mathrm{n}=2)$ and in random order to provide protection against the effect of hidden variables. The factors and experimental domain levels are presented in Table 2.

To know the optimal values of the factors that were the most influential according to the previous factorial design (temperature and volume of derivatizing reagent), a new experimental plan was applied. It consisted of a central composite design (CCD), the factors, levels, and 
Table 2. Factors, experimental domain and levels of factorial screening design $2^{3}$

\begin{tabular}{lccc}
\hline \multirow{2}{*}{ Factor } & \multicolumn{3}{c}{ Experimental domain } \\
\cline { 2 - 4 } & Level (-) & Center point & Level $(+)$ \\
\hline $\mathrm{t}_{\mathrm{rx}} / \mathrm{min}$ & 25.0 & 35.0 & 45.0 \\
$\mathrm{~T}_{\mathrm{rx}} /{ }^{\circ} \mathrm{C}$ & 25.0 & 30.0 & 35.0 \\
$\mathrm{~V}_{\mathrm{d}} / \mu \mathrm{L}$ & 5.0 & 12.5 & 20.0 \\
\hline
\end{tabular}

$\mathrm{t}_{\mathrm{rx}}:$ reaction time; $\mathrm{T}_{\mathrm{rx}}$ : reaction temperature; $\mathrm{V}_{\mathrm{d}}$ : volume of derivatizing reagent.

experimental domain, shown in Table 3. It should be noted that the time was not considered as an influential factor therefore its value was taken as $40 \mathrm{~min}$, according to the reported in the literature. ${ }^{15}$ The response variable was the area of the chromatographic peaks of the BAs.

Table 3. Factors, experimental domain and levels of design CCD $2^{2}$

\begin{tabular}{lccc}
\hline \multirow{2}{*}{ Factor } & \multicolumn{3}{c}{ Experimental domain } \\
\cline { 2 - 4 } & Level $(-)$ & Center point & Level $(+)$ \\
\hline $\mathrm{T}_{\mathrm{rx}} /{ }^{\circ} \mathrm{C}$ & 20.0 & 30.0 & 35.0 \\
$\mathrm{~V}_{\mathrm{d}} / \mu \mathrm{L}$ & 10.0 & 12.5 & 15.0 \\
\hline
\end{tabular}

$\mathrm{T}_{\mathrm{rx}}$ : reaction temperature; $\mathrm{V}_{\mathrm{d}}$ : volume of derivatizing reagent.

Final conditions of derivatization process

One milliliter of $2 \mathrm{~mol} \mathrm{~L}^{-1}$ sodium hydroxide and $15 \mu \mathrm{L}$ of benzoyl chloride were added sequentially to $2 \mathrm{~mL}$ of standard amines solution. The resulting solution was mixed with a vortex for $3 \mathrm{~min}$ and was left to react at room temperature for $40 \mathrm{~min}$. Later, $2 \mathrm{~mL}$ of $\mathrm{NaCl} 5 \mathrm{~mol} \mathrm{~L}^{-1}$ solution was added to the mixed solution, and we extracted it with $3 \mathrm{~mL}$ of diethyl ether. After centrifugation, the upper organic layer was transferred to a test tube, and evaporated to dryness under a steam of nitrogen. The residue was dissolved in $1 \mathrm{~mL}$ of methanol, and $20 \mu \mathrm{L}$ aliquots, previously filtered through PTFE membrane filter of $0.45 \mu \mathrm{m}$ (Millipore), were used for HPLC analysis.

\section{Extraction of biogenic amines in fish}

Fish meat samples (5 g) were homogenized with trichloroacetic acid, TCA (6\%). The mixture was centrifuged at $10.000 \mathrm{~g}$ for $10 \mathrm{~min}$ at $4{ }^{\circ} \mathrm{C}$, and filtered with Whatman No. 2. The extracts obtained were brought to a final volume of $50 \mathrm{~mL}$ with TCA. Finally, $2 \mathrm{~mL}$ of this extract were used in the derivatization process. ${ }^{15}$

\section{Results and Discussion}

Figure 1 shows the graphics of response surface obtained for the BAs using CCD design $2^{3}$, which represents the optimum response surface of every BA with respect to the variation of the wavelength and the column temperature. The optimal conditions of the model include a temperature of $30^{\circ} \mathrm{C}$, a wavelength of $230 \mathrm{~nm}$ and a flow of $0.8 \mathrm{~mL} \mathrm{~min}^{-1}$.

Under conditions of isocratic analysis, the analytes eluted as quickly or slowly as possible and the chromatographic peaks widened, resulting in inadequate resolution. To reach optimal separation of the compounds, an elution gradient was applied. Thus, based on elution gradient proposed by Tsai et al. ${ }^{16}$ successive tests were performed until the best resolution and efficiency in the chromatographic separation was achieved. The result from these analyses included shortening of retention times, sharp and symmetrical peaks, low retention factors and good resolution, thus fulfilling with desirable characteristics for BAs separation. Figure 2 shows the chromatogram results of the BAs separation eluted with the gradient of Table 4.

\section{Derivatization process}

In Pareto charts (Figures 3-5), we see factors from
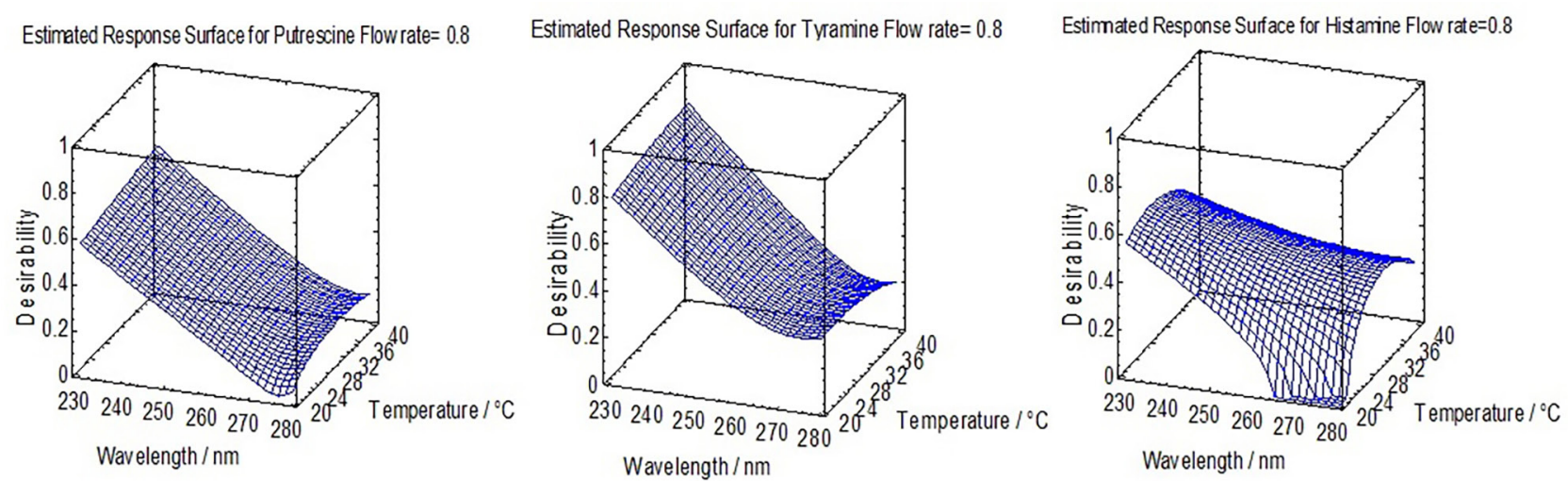

Figure 1. Tridimensional graphics of response surface. Variation in the response to changes in the temperature and wavelength factors. 


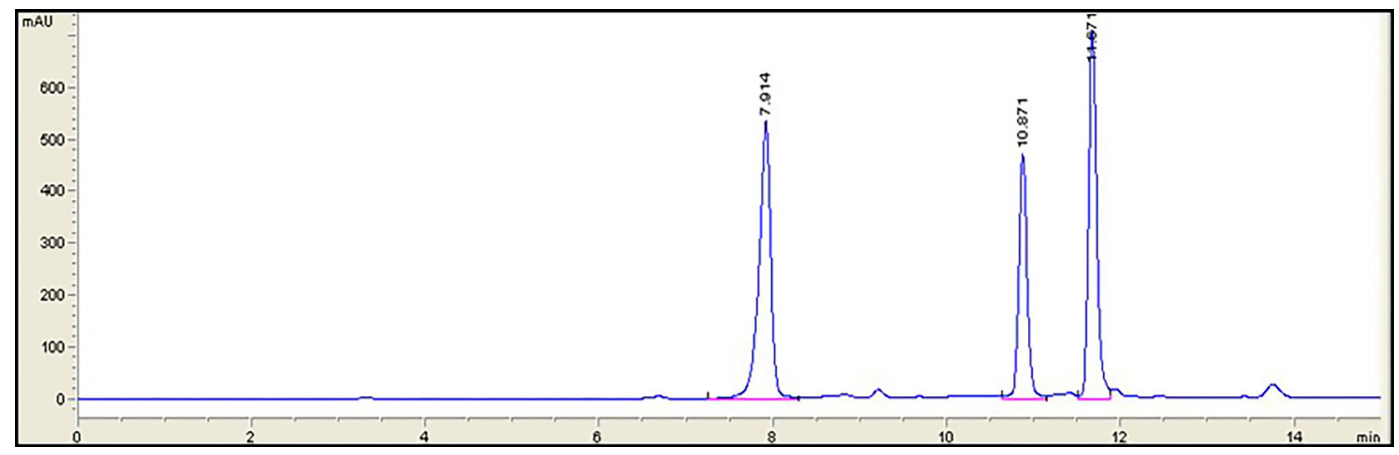

Figure 2. Chromatogram obtained for putrescine, histamine and tyramine $\left(50 \mathrm{mg} \mathrm{L}^{-1}\right)$ in gradient analysis conditions, by HPLC-UV.

Table 4. Gradient programmed for biogenic amines analyzing

\begin{tabular}{lcccc}
\hline Period & $\begin{array}{c}\text { time / } \\
\text { min }\end{array}$ & $\begin{array}{c}\text { Methanol / } \\
\mathrm{mL}\end{array}$ & $\begin{array}{c}\text { Water / } \\
\mathrm{mL}\end{array}$ & $\begin{array}{c}\text { Flow rate / } \\
\left(\mathrm{mL} \mathrm{min}^{-1}\right)\end{array}$ \\
\hline \multirow{3}{*}{ Elution } & 0.0 & 50 & 50 & \\
& 6.0 & 80 & 20 & 0.8 \\
& 7.0 & 85 & 15 & \\
\hline Return and balance & 12.0 & 85 & 15 & \\
\hline
\end{tabular}

high to low significance. Columns passing the vertical line (significance) show values significantly different from zero with a confidence level of $95.0 \%$ given by $p$-values of ANOVA.

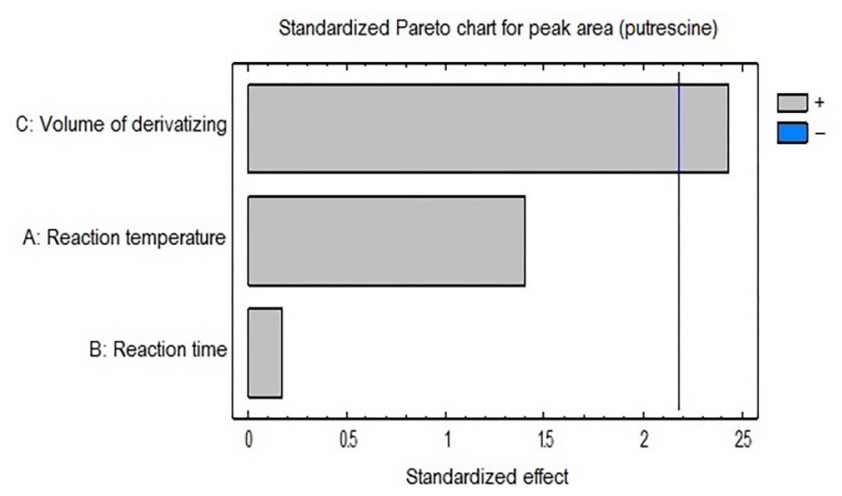

Figure 3. Standardized Pareto chart of factorial design $2^{3}$ for putrescine.
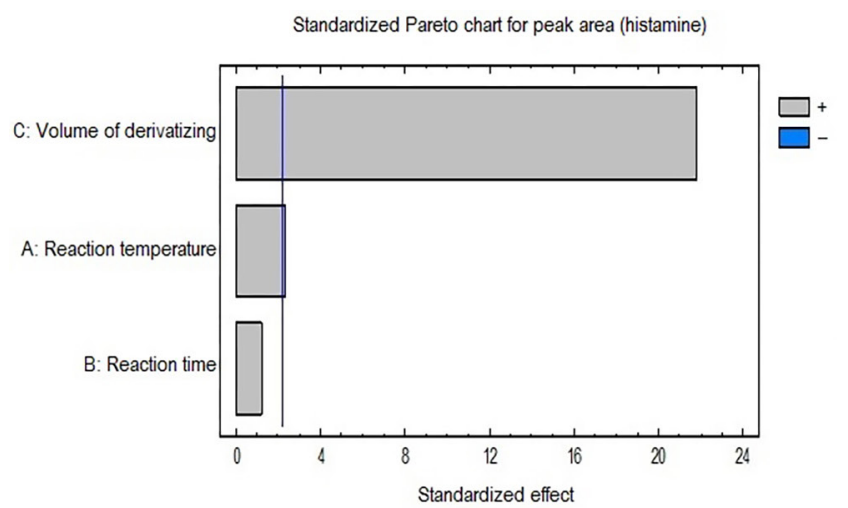

In this case, the volume of derivatizing reagent and reaction temperature were influential factors positively associated with the area of chromatographic peaks, i.e, an increase of these variables resulted in increased responses. Temperature offered the opposite effect on the number of interfering peaks. Time was not influential.

Table 5 shows the results obtained from the design $\mathrm{CCD} 2^{2}$, which indicate that for putrescine and histamine, the best signals resulted from the volume of derivatizing reagent of $15 \mu \mathrm{L}$ and a reaction temperature of $30^{\circ} \mathrm{C}$, and for tyramine, the best signal resulted from the volume of derivatizing reagent of $15 \mu \mathrm{L}$ and a reaction temperature of $20^{\circ} \mathrm{C}$.
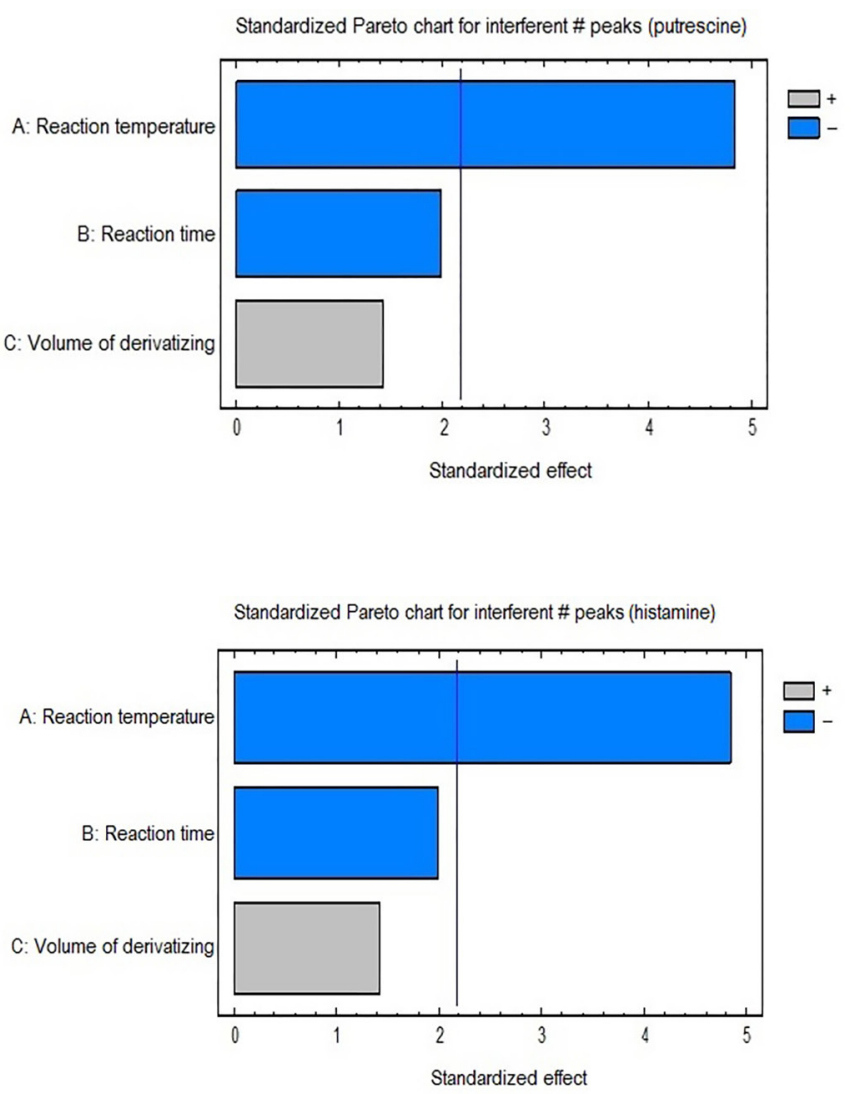

Figure 4. Standardized Pareto chart of factorial design $2^{3}$ for histamine. 

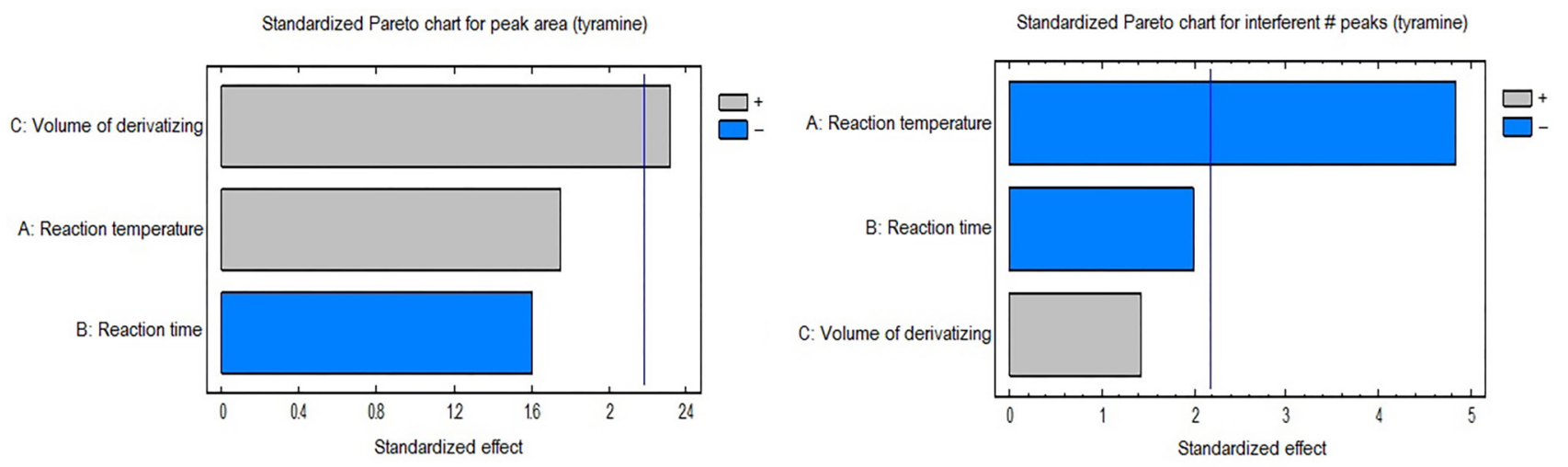

Figure 5. Standardized Pareto chart of factorial design $2^{3}$ for tyramine.

Table 5. Experimental plan and results for design CCD $2^{2}$ by HPLC-UV

\begin{tabular}{|c|c|c|c|c|c|c|}
\hline \multirow{3}{*}{ Experiment } & \multicolumn{2}{|c|}{ Factors } & \multicolumn{3}{|c|}{ Response variable } & \multirow{3}{*}{ \# IP } \\
\hline & \multirow{2}{*}{$\mathrm{V}_{\mathrm{d}} / \mathrm{mL}$} & \multirow{2}{*}{$\mathrm{T} /{ }^{\circ} \mathrm{C}$} & Putrescine & Histamine & Tyramine & \\
\hline & & & A / (ma.u. s) & A / (ma.u. s) & A / (ma.u. s) & \\
\hline 1 & 10.0 & 35 & 3654 & 753 & 2639 & 0 \\
\hline 2 & 12.0 & 30 & 4065 & 953 & 2754 & 0 \\
\hline 3 & 10.0 & 20 & 3302 & 830 & 3186 & 0 \\
\hline 4 & 12.5 & 20 & 3909 & 968 & 3235 & 0 \\
\hline 5 & 15.0 & 20 & 4321 & 1549 & 3408 & 0 \\
\hline 6 & 15.0 & 35 & 3640 & 1450 & 0 & 2 \\
\hline 7 & 12.5 & 30 & 4049 & 961 & 2770 & 1 \\
\hline 8 & 10.0 & 30 & 3618 & 901 & 2880 & 0 \\
\hline 9 & 15.0 & 30 & 4426 & 1675 & 1687 & 1 \\
\hline 10 & 12.5 & 35 & 3920 & 893 & 0 & 2 \\
\hline
\end{tabular}

$\mathrm{V}_{\mathrm{d}}$ : volume of derivatizing reagent (benzoyl chloride); A: area; \# IP: number of interferent peaks.

Figure 6 shows the surface graphs obtained for the BAs by HPLC using CCD design surface $2^{2}$, representing variation in response with reaction temperature change and amount of volume of derivatizing reagent. It can be seen a positive association between the temperature decrease and volume increase of derivatizing reagent to increase chromatographic peaks area with fewer interferences.

Through an analysis of multiple response, the statistical software calculated the optimal reaction conditions for each BA, corresponding to $20^{\circ} \mathrm{C}$ and $15 \mu \mathrm{L}$.

Table 6 shows the efficiency parameters for chromatographic separation of putrescine, histamine
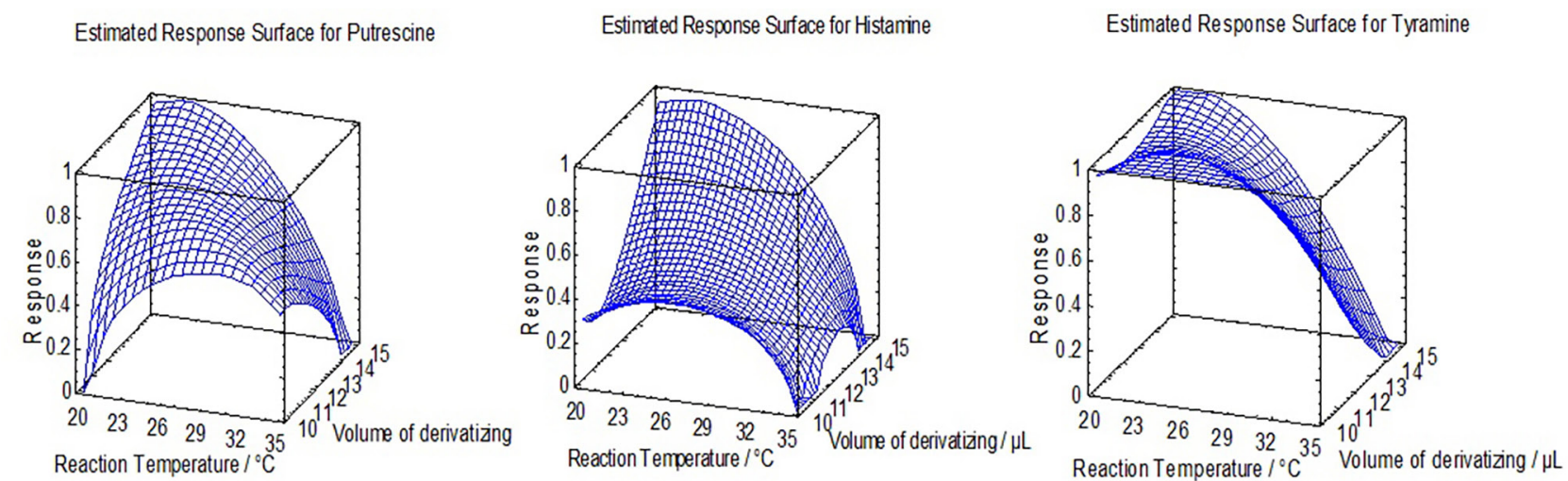

Figure 6. Tridimensional graphics of response surface of $\mathrm{CCD} 2^{2}$ for putrescine, histamine and tyramine. 
Table 6. Parameters of efficiency for chromatographic separation of biogenic amines

\begin{tabular}{|c|c|c|c|c|c|c|c|}
\hline Peak & $t_{R} / \min$ & A / (ma.u. s) & $\mathrm{S}$ & $\mathrm{k}^{\prime}$ & $\alpha$ & $\mathrm{R}_{\mathrm{s}}$ & $\mathrm{N}$ \\
\hline Putrescine & 7.930 & 20813 & 1.411 & 2.5 & - & - & 49689 \\
\hline Histamine & 10.911 & 7592 & 0.846 & 3.8 & 1.5 & 23.9 & 166684 \\
\hline Tyramine & 11.715 & 14529 & 0.857 & 4.2 & 1.1 & 7.8 & 220026 \\
\hline
\end{tabular}

S: symmetry factor; k': capacity factor or retention; $\alpha$ : selectivity factor; $\mathrm{R}_{\mathrm{s}}$ : resolution; $\mathrm{N}$ : number of theoretical plates.

and tyramine determined under optimum operating conditions.

Capacity factors or retention $\left(\mathrm{k}^{\prime}\right)$ range from 2.5 to 4.2, which relates to a suitable rate of migration of the analytes. The selectivity factors $(\alpha)$ were greater than unity indicating that the column provides good separation of the analytes. Resolution values $\left(\mathrm{R}_{\mathrm{s}}\right)$ indicate that the chromatographic peaks were successfully separated with a minimum acceptance limit value of 1.5 recommended by Skoog and co-workers. ${ }^{16}$

Having established the method, calibration curves for the three BAs were performed and the method was applied to spiked fish samples with standard solutions of putrescine, histamine and tyramine at concentrations of 50,80 and $50 \mathrm{mg} \mathrm{L}^{-1}$, respectively. We had recovery rates in a range of 90.89 to $96.65 \%$ for putrescine; 93.36 to $95.87 \%$ for histamine; 86.57 to $93.33 \%$ for tyramine, with the relative standard deviation (RSD) less than 4\%. Recovery rate was calculated by comparing the amount of each BA detected in the spiked food matrix with the amount of each standard material added to food matrix. The analysis was conducted 9 times, and results of RSD and recovery studies are given in Table 7. The average recovery of all BAs and RSD are within the expected ranges. ${ }^{17}$

Table 7. Application of the method on fish meat samples spiked with biogenic amines and determination of their average recovery

\begin{tabular}{lccc}
\hline \multirow{2}{*}{ Replica } & $\begin{array}{c}\text { Putrecine } \\
\left(50 \mathrm{mg} \mathrm{L}^{-1}\right)\end{array}$ & $\begin{array}{c}\text { Histamine } \\
\left(80 \mathrm{mg} \mathrm{L}^{-1}\right)\end{array}$ & $\begin{array}{c}\text { Tyramine } \\
\left(50 \mathrm{mg} \mathrm{L}^{-1}\right)\end{array}$ \\
\cline { 2 - 4 } 1 & \multicolumn{3}{c}{ Recovery / \% } \\
2 & 91.17 & 93.50 & 87.32 \\
3 & 90.92 & 93.55 & 86.99 \\
4 & 90.89 & 93.36 & 86.57 \\
5 & 96.56 & 94.64 & 92.26 \\
6 & 96.47 & 95.48 & 92.16 \\
7 & 96.65 & 95.87 & 93.33 \\
8 & 91.80 & 94.99 & 93.19 \\
9 & 91.84 & 95.61 & 88.36 \\
RSD & 91.65 & 95.23 & 87.16 \\
\hline
\end{tabular}

RSD: relative standard deviation.

\section{Conclusions}

The analytical methodology developed was optimized by experimental design using multiple response analysis. The optimal conditions for the derivatization process were: $15 \mu \mathrm{L}$ of benzoyl chloride, $20{ }^{\circ} \mathrm{C}$ of temperature and 40 minutes of reaction. The optimal conditions for chromatographic separation and detection were: a gradient system (methanol:water), flow $0.8 \mathrm{~mL} \mathrm{~min}{ }^{-1}$, column temperature of $30^{\circ} \mathrm{C}$ and a wavelength of $230 \mathrm{~nm}$. Finally, the method was applied in spiked fish samples with standard solutions of putrescine, histamine and tyramine at concentrations of 50,80 and $50 \mathrm{mg} \mathrm{L}^{-1}$, respectively, to get recovery rates in a range of 90.89 to $96.65 \%$ for putrescine; 93.36 to $95.87 \%$ for histamine; 86.57 to $93.33 \%$ for tyramine, with RSD less than $4 \%$.

\section{Acknowledgments}

The authors acknowledge the funding and support from the Vicerrectoría de Investigaciones, Postgrados y Relaciones Internacionales (VIPRI) of the University of Nariño, the Instituto Departamental de Salud de Nariño (IDSN) specially to pharmaceutical chemist Lucy Bravo, the foundation Centro de Estudios Interdisciplinarios Básicos y Aplicados (CEIBA), the Group of Investigation Estudio de Sistemas Contaminantes (GIESIC) specially to chemist David Perdomo, and the Centro de Estudios en Salud de la Universidad de Nariño (CESUN).

\section{References}

1. Önal, A.; J. Agric. Food Chem. 2013, 138, 509.

2. Önal, A.; J. Agric. Food Chem. 2007, 103, 1475.

3. Ruiz, C.; Jiménez, F. C.; Food Chem. 2009, 112, 487.

4. Official Methods of Analysis of AOAC International, Method 957.07: Histamine in Seafood: Chemical Method, Section 35.5.31, $16^{\text {th }}$ ed.; Cunniff, P. A., ed.; AOAC: Gaithersburg, 1995, p. 15.

5. Sun, J.; Guo, H. X.; Semin, D.; Cheetham, J.; J. Chromatogr. A 2011, 1218, 4689.

6. Patange, S. B.; Mukundan, M. K.; Ashok, K.; Food Control. 2005, 16, 465 . 
7. Official Methods of Analysis of AOAC International, Method 977.13: Histamine in Seafood: Fluorometric Method, Section 35.1.32, 16 th $^{\text {th }}$.; Cunniff, P. A., ed.; AOAC: Gaithersburg, 1995, p. 6.

8. Šimat, V.; Dalgaard, P.; Int. J. Food Sci. Technol. 2011, 44, 399.

9. Arrieta, M. P.; Prats-Moya, M. S.; Food Chem. 2012, 135, 1511.

10. Hernández-Cassou, S.; Saurina, J.; J. Chromatogr. A 2011, 879, 1270.

11. Salazar, P.; García, M. L.; Selgas, M. D.; Int. J. Food Sci. Technol. 2009, 44, 1100.

12. Köse, S.; Koral, S.; Tufan, B.; Pompe, M.; Scavniçar, A.; Koçar, D.; Eur. Food Res. Technol. 2012, 235, 669.

13. Henríquez-Aedo, K.; Vega, M.; Prieto-Rodríguez, S.; Aranda, M.; Food Chem. Toxicol. 2012, 50, 2742.
14. Zarei, M.; Najafzadeh, H.; Enayati, A.; Pashmforoush, M.; J. Toxicol. Sci. 2011, 3, 190.

15. Tsai, Y.; Kung, H.; Lee, T.; Chen, H.; Chou, S.; Wei, C.; Hwang, D.; Food Control 2005, 16, 579.

16. Douglas, A.; Skoog, D. M.; West, F.; James, H.; Stanley, R.; Fundamentos de Química Analítica, ${ }^{\text {th }}$ ed.; Cengage Learning: Massachusetts, Estados Unidos, 2015.

17. European Comission; 2002/657/EC: Commission Decision of 12 August 2002 Implementing Council Directive 96/23/EC Concerning the Performance of Analytical Methods and the Interpretation of Results; Official Journal of the European Communities, 2002, L 221, p. 8.

Submitted: May 16, 2016 Published online: July 4, 2016 